\title{
Time Is the Fire in Which We Burn (Out): How Time Perspectives Affect Burnout Tendencies in Health Care Professionals Via Perceived Stress and Self-Efficacy
}

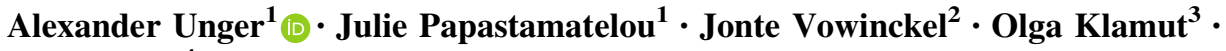 \\ Anja Heger ${ }^{4}$
}

Received: 30 May 2021 / Accepted: 4 January 2022/Published online: 15 February 2022

(C) The Author(s) 2022

\begin{abstract}
Aim and Background: The purpose of the current study is to examine the influence of time perspectives (TP) on the burnout-tendency of health care professionals. The concept of TP delivers a construct on how individuals frame their thinking and behavior on the emotional, cognitive and motivational level towards the past, the present and the future. Consequently, we assume that the TP configuration of health care professionals, determines how vulnerable or reluctant they will be to burnout. TP is assumed to influence the stress perception and the degree of self-efficacy which are in turn well-known factors of influence on burnout. Methods: The sample consisted of 398 health care professionals in Germany. We have measured TPs by the Zimbardo Time Perspective Inventory (ZTPI) and the burnout tendencies by the German version of the Maslach Burnout-Inventory (MBI-GS-D). Results: The Past-Negative and Past-Positive perspectives were identified as factors that were significantly associated with the burnout dimensions of emotional exhaustion, cynicism and personal accomplishment. The Present-Fatalistic orientation was only associated with cynicism and the Future dimension with cynicism and personal accomplishment. Furthermore, we observed that high deviations from a Negative Time Perspective (DNTP) caused a decrease on all three burnout dimensions. In addition, the influence of
\end{abstract}

Alexander Unger

alunger@web.de

1 Ludwigshafen University of Business and Society, Ernst-

Böhe-Str. 4, 67059 Ludwigshafen am Rhein, Germany

2 Bonn, Germany

3 Charles University, Prague, Czech Republic

4 Practice for Psychotherapy, Cologne-Marienburg, Germany the DNTP on emotional exhaustion, cynicism and personal accomplishment was fully mediated by perceived stress and self-efficacy. Conclusion: We identified time perspective as a substantial factor of influence on burnout for health care professions and observed an underlying mechanism of the influence of DNTP on burnout. Both factors are important for practical therapeutic conclusions, as well as for a better understanding of the role of TP for burnout.

Keywords Burnout - Time perspectives · Perceived stress · Self-efficacy $\cdot$ Health care professionals

\begin{tabular}{|c|c|c|c|}
\hline \multicolumn{4}{|c|}{ Abbreviations } \\
\hline DBTP & \multicolumn{3}{|c|}{ Deviation from a Balanced Time Perspective } \\
\hline DNTP & \multicolumn{3}{|c|}{ Deviation from a Negative Time Perspective } \\
\hline $\mathrm{F}$ & \multicolumn{3}{|l|}{ Future } \\
\hline MBI-GS & Maslach & Invent & ry-General \\
\hline & \multicolumn{3}{|l|}{ Survey } \\
\hline MBI-GS-D & German Maslach & Burnout & Inventory- \\
\hline & \multicolumn{3}{|l|}{ General Survey } \\
\hline PSQ & \multicolumn{3}{|c|}{ Perceived Stress Questionnaire } \\
\hline SES & \multicolumn{3}{|l|}{ Self-efficacy Scale } \\
\hline $\mathrm{PF}$ & \multicolumn{3}{|l|}{ Present Fatalistic } \\
\hline $\mathrm{PH}$ & \multicolumn{3}{|l|}{ Present Hedonistic } \\
\hline PN & \multicolumn{3}{|l|}{ Past Negative } \\
\hline PP & \multicolumn{3}{|l|}{ Past Positive } \\
\hline ZTPI & \multicolumn{3}{|c|}{ Zimbardo Time Perspective Inventory } \\
\hline
\end{tabular}

\section{Abbreviations}

DBTP Deviation from a Balanced Time Perspective

DNTP Deviation from a Negative Time Perspective

$\mathrm{F}$

ZTPI 


\section{Introduction}

Studies which address the influence of time-perspectives (TPs) on the burnout tendency of occupational samples are rare. Akirmak and Ayla (2021) reported that Deviation from a Balanced Time Perspective (DBTP) enhances the burnout proneness of bank employees. Another study by Meidani et al. (2019) observed correlational associations of the individual TP dimensions to the burnout phenomenon among a sample of teachers. Similar results were reported by Detaille et al. (2020) for blue-collar workers in the naval sector. Two other studies, one with a sample of a variety of blue-collar workers from Spain (Reig-Botella et al., 2021) and another with a sample of industrial workers versus MBA-students (Papastamatelou \& Unger, 2018) were able to show that differences in burnout proneness across several branches and professions depend on differing TPs in these branches and professions.

Research on burnout could further benefit from the inclusion of TP-theory. We assume that some TPs may increase vulnerability, while others may attenuate the level of burnout severity. The most significant factors reported in the literature that trigger burnout tendencies are organizational factors (Maslach \& Leiter, 2000), but individuals may also show different levels of burnout-vulnerability (Langelaan et al., 2006). Following Lewin's (1936) concept of behavior as a function of environmental and personal factors, burnout can be understood as resulting from an interaction of organizational and personal factors.

Burnout is a widespread and severe phenomenon, that has been observed across many different branches and professions. Once systematic occupational burnout-research was intensified in the USA in the seventies one important focus was on the health care sector, and on other service professions (Schaufeli, 2017).

The health care staff together with several other professionals, such as teachers (Bernotaite \& Malinauskiene, 2017) or police officers (Talavera-Velasco et al., 2018), have the highest burnout risk due to factors like high emotional stress levels or heavy work burden (Bridgeman et al., 2018). Also Moss et al. (2016, p. 1414) summarize the professions with the highest risk for burnout as following: "[...] burnout syndrome [...] has become a common worldwide phenomenon, especially among members of high-stress professions: firefighters, police officers, teachers, and all types of health care professionals." The substantial and specific reasons for the high vulnerability of burnout among health care professionals across many countries including Germany are at least two-fold: the considerable emotional straining aspects in the interaction with very ill or dying patients and the high workload due to lack of staff and additional administrative tasks (Kane, 2019; Messias et al., 2019).

For a better understanding of the phenomenon, as well as of the interplay between personality and organizational variables it is necessary to identify the relevant influence factors on all levels. One new promising approach is TP. The first purpose of the current study, is to extend the TP effects of burnout on the health care sector. The second purpose, is to test possible underlying mechanisms in a mediator model. This could help to improve the understanding of the association between time perspective and burnout proneness.

We will explain the conceptual characteristics of the TP construct. Afterward, we will introduce the association of $\mathrm{TP}$ and the assumed mediator variables, perceived stress and self-efficacy. Moreover, we will discuss why and how these variables influence the burnout proneness on all three burnout dimensions: emotional exhaustion, cynicism and (reduced) personal accomplishment.

\section{The Time Perspective Construct}

In the present study, we focus on the individual differences in the construct of time perspective (TP). TPs are defined as the "[...] often non-conscious process whereby the continual flows of personal and social experiences are assigned to temporal categories, or time frames, that help to give order, coherence, and meaning to those events" (Zimbardo \& Boyd, 1999, p. 1271). When becoming habituated, TPs can be interpreted as relatively stable individual variables. TP can be understood as a general reference system which includes the past, the present and the future while consisting of behavioral, emotional, motivational and cognitive components. For example, depending on the scoring on each TP dimension the interpretation or perception of the past, present and future differs in many ways. In addition, behavioral acts can be influenced in various ways. Each of these aspects was shown in several empirical studies during the last two decades.

It is important to differentiate the TP-concept by Zimbardo and Boyd (1999) from related psychological research approaches on time, as well as from other former time perspective concepts.

TP is different from approaches that capture specific important aspects as the subjective perception of time duration (Wittmann, 2013; Zakay \& Block, 1997), different preferences for activity during mornings versus evenings, known as biological circadian-based rhythm (Pruszczak et al., 2017), and behavioral consequences of perceived time pressure (Svenson \& Maule, 1993). In contrast, TP is conceptualized as a global construct (Stolarski et al., 2018). Several studies investigated the relation of TP and these 
more specific approaches, such as Witowska et al. (2020) for TP and time perception or Stolarski et al. (2013a, 2013b) for TP and chronotypes.

Similarly, we need to differentiate the TP-concept by Zimbardo and Boyd (1999) from other existing time perspective concepts, such as the consideration of the future consequences scale by Strathman et al. (1994) or the future anxiety scale by Zaleski (1996) and to clarify the unique features of the first concept (cf. for an overview of the numerous former approaches Stolarski et al., 2018).

The essential difference between the TP-concept by Zimbardo and Boyd (1999) and all other concepts of TP is that the first one captures the past, the present and the future, whereas the others only measure one dimension. These concepts assume that for example a high future score would inevitably imply a low present orientation and vice versa. This type of a unilateral temporal focus is not assumed in the TP-concept. Instead, it provides all possible combinations of TP-dimensions, resulting in different TPprofiles (cf. Boyd \& Zimbardo, 2005, pp. 98-100). Typically, some of these combinations or TP-profiles are issued as biased or unbalanced if one or several TP-dimensions are pronounced, while others show very low values. Those biased TP profiles are not assumed to occur inevitably. For example a high score of an individual on the Future TP can occur simultaneously with a high score on the Present Hedonistic TP.

To summarize, the TP-concept enables the measurement of an overall-configuration of all TP-dimensions. Furthermore, it captures more aspects than do other TP-related approaches. Shipp et al. (2009) give a systematic and conceptual overview of temporal focus approaches, as well as of other TP-related approaches. Following Shipp et al. (2009) temporal focus approaches are about the attention an individual allocates to the past, present and future, and the time attitude approach (Nuttin, 1985) is about the positive and negative effects toward the past, present and future. In contrast, (cf. Shipp et al., 2009), TP is characterized as an overarching framework that includes cognition, affect and behavior. Consequently, the TP construct also specifies how the past, present and future is evaluated and interpreted.

The ZTPI, the most commonly used scale to assess TPs, distinguishes five sub-constructs: Past-Positive, PastNegative, Present-Fatalistic, Present-Hedonistic and Future. Boniwell and Zimbardo (2004) emphasize that it is not the influence of each single TP that plays a determining role for various behavioral domains, but instead their overall configuration. The overall configuration mostly refers to the concept of a Balanced Time Perspective. In the current study, we use the Deviation from a Negative Time Perspective (DNTP). A Negative Time Perspective is defined by a score high on the Past-Negative and Present-
Fatalistic, and a low score on Past-Positive, Future and Present-Hedonistic.

Potentially relevant links between TPs and a vulnerability to burnout are TPs' associations with depression (van Beek et al., 2011), life satisfaction (Zhang \& Howell, 2011), mood (Stolarski et al., 2015), emotional, psychological and social well-being (Vowinckel et al., 2015), emotional intelligence (Stolarski et al., 2011), mindfulness (Stolarski et al., 2016), frequency of flow-experiences at the workplace (Vowinckel et al., 2015), and neuroticism and extraversion (Dunkel \& Weber, 2010).

We argue that the TP-concept can provide new explanations with respect to burnout and that some configurations of the five time dimensions will be helpful in avoiding the risk of burnout, whereas others will enhance the burnout tendency.

\section{The Association of Self-Efficacy and Perceived Stress to Burnout}

It has been indicated that self-efficacy is important for functioning (Luszczynska et al., 2005). A high self-efficacy constitutes a resource that can support the prevention of burnout symptoms, since it enables people to trust in their own abilities and to remain optimistic, in order to cope efficiently with heavy workload or enormous requirements. The relationship between perceived self-efficacy (Bandura, 1977) and burnout has been investigated in several studies (Schwarzer \& Hallum, 2008; Skaalvik \& Skaalvik, 2010). These studies conclude that self-efficacy plays an important role in burnout inhibition. The perceived stress level is another well documented enhancing factor of influence on burnout (Kokkinos, 2007; Lloyd et al., 2002).

\section{The Association of Time Perspectives (TPs) on Self-Efficacy and Perceived Stress}

The assumed influence of TPs on both considered mediators can be supported by theoretical reasoning and empirical data. For one thing, an immense and growing body of research has shown that TPs are essential for a wide range of behaviors, as well as adaptive psychological functioning (Boniwell \& Zimbardo, 2004).

Individuals with a pronounced Past-Positive orientation usually show a more stable personality (Kairys \& Liniauskaite, 2015) and higher self-esteem (Zimbardo \& Boyd, 1999). Individuals scoring high on the Future orientation are more efficient in striving to reach goals (Zaleski \& Przepiórka, 2015) and usually experience success more often, while they are more optimistic in general (Zimbardo \& Boyd, 1999). A pronounced Future TP may contribute to 
increased self-control and better problem solving. However, high scores on the Future perspective may also be a source of stress (Zimbardo \& Boyd, 1999) if work engagement turns into permanent over-commitment.

For the Past-Negative and Present-Fatalistic orientations, low values result in less perceived stress, whereas high values are associated with increased helplessness (Chen et al., 2016a, 2016b), resulting in maladaptive stresscoping strategies and higher levels of emotional stress (Oyanadel \& Buela-Casal, 2014). Zajenkowski et al. (2016) identified Present-Fatalistic and Past-Negative perspectives related to high stress levels. Furthermore, Stolarski et al. (2013a, 2013b) observed higher arousal and stress levels for a pronounced Past-Negative orientation. Papastamatelou et al. (2015) identified Present-Fatalistic and Past-Negative orientations as being highly correlated with perceived stress.

TP research has revealed that the choice of stress coping strategies which are applied by individuals depend on specific TPs: Bolotova and Hachaturova (2013) concluded that the Future and the Past-Positive perspectives correlate with adaptive stress coping strategies, whereas the PresentFatalistic and in particular the Past-Negative dimension correlate with maladaptive ones. The relationship between stress coping strategies and TPs involves also endocrine processes as demonstrated by Olivera-Figueroa et al. (2015) who showed that high scores of (adaptive) Deviation from DNTP correlate with those cortisol release patterns that reflect better stress coping.

The results of self-efficacy studies, have shown that low scores on the Present-Fatalistic and high scores on the Future dimension have been identified as factors promoting high self-efficacy (Epel et al., 1999). Based on these results, we assume that a high DNTP, will result in higher levels of self-efficacy.

Since perceived stress and self-efficacy depend on TPs, these factors can have in turn substantial influence on burnout. Consequently, we tested the hypothesized influence of TPs on burnout, and the mediating role of both factors on this influence.

\section{Derivation of the Hypotheses}

We assume that the Past-Negative TP is positively associated with burnout tendencies, since it comes along with a negative attribution style and a pessimistic expectation about one's coping possibilities. A close relationship between Past-Negative orientation and negative mood, high anxiety, and depression has been reported by Zimbardo and Boyd (1999). The Past-Negative dimension is positively correlated and the Past-Positive orientation is negatively correlated to neuroticism. In addition, Past-
Negative orientation is negatively correlated whereas PastPositive orientation is positively correlated to extraversion (Kairys \& Liniauskaite, 2015). Extraversion is negatively related to burnout and neuroticism is positively related to burnout tendencies (Bakker et al., 2006). Thus, it can be assumed that a high Past-Positive perspective supports a stable personality as a bolster against burnout. A PresentFatalistic perspective is accompanied by feelings of helplessness and low self-efficacy. Thus, adaptive coping strategies are reduced, which, in turn, may facilitate burnout tendencies.

A high scoring on the Present-Hedonistic perspective may deliver compensation and relaxation from exhausting achievement. As outlined by Zimbardo and Boyd (1999), a high Present-Hedonistic perspective is also associated with openness toward new experiences and retention of childlike curiosity (van Beek et al., 2011). Thus, the PresentHedonistic perspective can be expected to be negatively associated with burnout. As argued by Boniwell and Zimbardo (2004), people who show a pronounced Future perspective have difficulties enjoying the present. They are efficient in functioning at their workplace, but they may not be able to relax and recover. We assume that the PastPositive and the Present-Hedonistic perspectives are negatively associated with burnout tendencies, whereas the Past-Negative, Present-Fatalistic and the Future dimensions are positively associated with burnout symptoms.

Moreover, we assume that a high DNTP will reduce burnout tendencies on all three dimensions and that selfefficacy and perceived stress mediate this influence of DNTP on burnout. More precisely, we assume the higher the DNTP, the lower the level of perceived stress and the higher the self-efficacy. In turn, the higher the perceived stress is, the higher the burnout will be; and the higher the self-efficacy is, the lower the burnout will be. All hypotheses were tested for all three burnout dimensions separately.

\section{Methods}

\section{Participants}

In the current study, the sample consisted of 301 female and 70 male (27 did not indicate their gender) German health care professionals $(\mathrm{N}=398)$ who may be at risk for burnout $\left(\mathrm{M}_{\mathrm{age}}=27.1\right.$ years $\mathrm{SD}=10.5$ years $)$. The sample consists of the following age-groups: $15-20$ years $(29.6 \%)$, 21-30 years $(45.7 \%), 31-40$ years $(11.8 \%), 41-50$ years (6.7\%), 51-60 years (5.6\%) and $61-70$ years $(0.5 \%)$, reflecting a broad range of ages $\left(\operatorname{Min}_{\mathrm{AGE}}=15\right.$ years and $\operatorname{Max}_{\mathrm{AGE}}=67$ years), with younger participants being over-represented and older participants being under- 
represented. The health care professionals of our sample consist of three groups with a very similar occupational profile and with very comparable professional burdens and obligations. The overwhelming majority belongs to the group of health care professionals working in hospitals (69.3\%), the second largest group consists of geriatric caregivers working in retirement homes with inhabitants who need permanent care (19.8\%). Finally, a smaller group consists of geriatric caregivers working in mobile caregiving stations $(10.8 \%)$. In Germany, the profession of health care, including all three aforementioned groups, is a regulated profession which requires official recognition. Thus, we included only health care employees that have the required regular vocational training, resulting in a relatively homogeneous sample in accordance with the quality of their vocational training. All data was collected in the cooperating institutions. Voluntariness and strict anonymity were emphasized during the recruitment process. Furthermore, all participants were informed that they can leave the study at any time. To ensure anonymity we used ballot boxes in all sites of the study. After finishing the datacollection all participants were debriefed on the purpose of the study.

\section{Measures}

\section{Zimbardo Time Perspective Inventory (ZTPI) and Deviation from a Negative Time Perspective (DNTP)}

We used the validated German short version of the ZTPI (Danner et al., 2019). The scale consists of ten Items with two for each TP dimension. The scale has a 5-item response format ranging from 1 (=fully disagree) to 5 (= fully agree). Danner et al. (2019) reported relatively low Cronbach's Alpha (between 0.40 and 0.63) for the five TP subscales and emphasized with reference to the work of Credé et al. (2012) and by Rammstedt and John (2007), that these values are comparable to other short scales. Danner et al. also confirmed the five dimensional factor structure of the short version (p. 176). Based on this version we applied the calculation of the five TPs (Zimbardo \& Boyd, 1999) and the calculation of the DNTP as maladaptive TP profile, which was developed by Oyanadel and Buela-Casal (2014). The formula for the DNTP calculation is as follows:
In this formula $n$ equals the observed negative value obtained for each measured TP, whereas $e$ equals the $e x$ pected negative value for each TP [4.35 for Past-Negative (PN), 2.80 for Past-Positive (PP), 3.30 for Present-Fatalistic (PF), 2.65 for Present-Hedonistic (PH), and 2.75 for Future (F)]. The negative reference values were developed and defined by Zimbardo et al. (2012), on the basis of theoretical considerations and on the high similarity to the empirical measured TP profiles of patients, suffering from Post-Traumatic-Stress-Disorder (PTSD). Several studies have confirmed the relevance of the DNTP for other mental health issues (Oyanadel \& Buela-Casal, 2014, 2017) and for aspects of well-being in general (Oyanadel et al., 2014). For a detailed discussion of different balanced and unbalanced TP measurements cf. Kairys et al. (2017) and for a sceptical review McKay and Cole (2020).

We chose the DNTP over the DBTP because we assume that the non-existence of negative aspects is more relevant, than the distance to the positive effects of a balanced TP for the development of burnout. We assume that a high DBTP score has primarily high reducing effects on wellbeing, life satisfaction or related constructs. A high DBTP, however, will not automatically cause a substantial higher burnout risk. In contrast we assume, that an individual with a very low DNTP score (compared to a high DNTP score) has a much higher burnout risk, because a low DNTP would imply high scores of the problematic TPs of Present Fatalistic and Past Negative. To summarize, we do not argue that the DBTP may be entirely irrelevant for burnout, but we argue that the DNTP has more relevance than the DBTP. McKay and Cole (2020) conclude however from their study about the association between DBTP and DNTP with anxiety and depression that more research is needed for both in particular before a therapeutic application can be justified. Additionally, we conducted hierarchical linear regression analysis (HLRA) with both overall configurations of DBTP and DNTP (utilizing the stepwise method) on all three burnout dimensions to test also empirically which of them should be used in the main analysis. In all three analysis DBTP was excluded from the model and did not reach significance (emotional exhaustion: $p=0.085$; cynicism: $\quad p=0.414$; personal accomplishment: $p=0.349$ ), whereas DNTP remained included in each of the resulting models. DNTP reached significance in predicting emotional exhaustion $(\beta=-0.278, B=-0.372$, SE $\quad B=0.068, \quad t=-5.450, \quad p<0.001), \quad$ cynicism $(\beta=-0.250, \quad B=-0.309$, SE $B=0.063, \quad t=-4.928$,

$D N T P=\sqrt{(n P N-e P N)^{2}+(n P P-e P P)^{2}+(n P F-e P F)^{2}+(n P H-e P H)^{2}+(n F-e F)^{2}}$ 


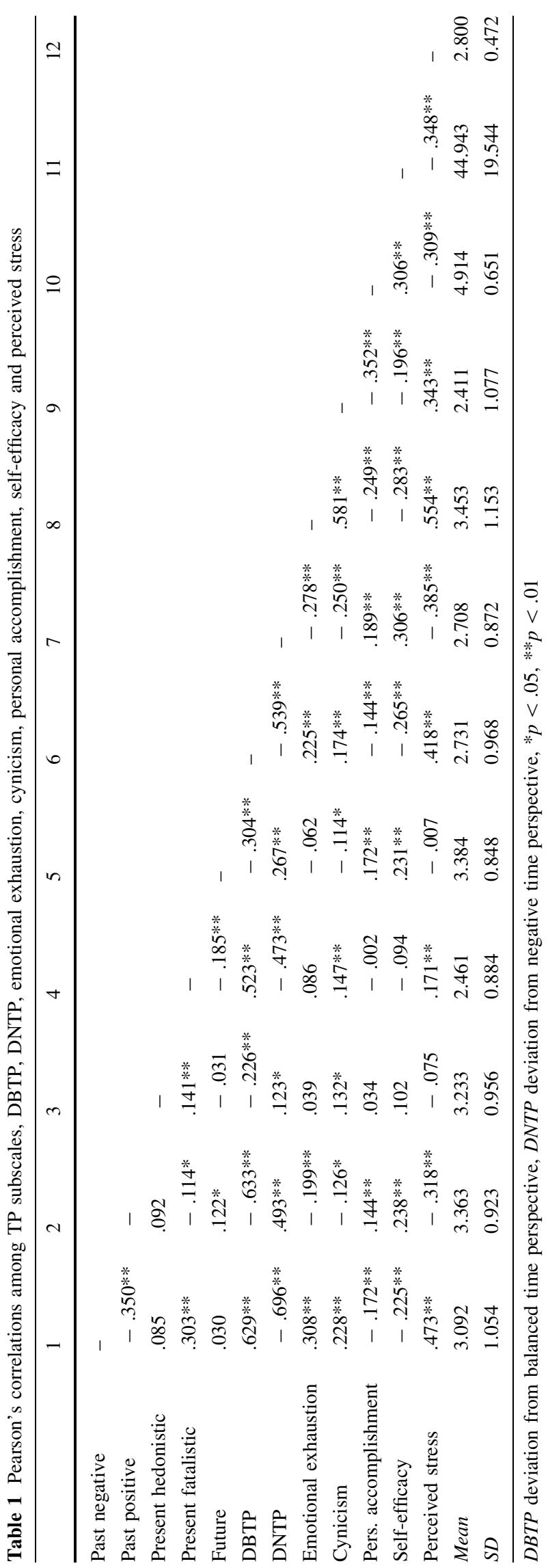

$p<0.001)$ and personal accomplishment $((\beta=0.189$, $B=0.142, S E B=0.189, t=3.642, p<0.001)$.

\section{Maslach Burnout Inventory (MBI)}

We used the German version-MBI-GS-D-(Büssing \& Glaser, 1998) of the general Maslach-Burnout-InventoryMBI-GS-(Schaufeli et al., 1996) for measuring the three dimensions of burnout tendency: Emotional exhaustion, cynicism, and personal accomplishment (reverse-coded). The MBI-GS-D consists of 16 items with five items for emotional exhaustion, five items for cynicism, as well as with six items for personal accomplishment. The scale has a 6-item response format ranging from 1 (= never) to 6 (= very often). The original three dimensional structure is well confirmed (Schaufeli et al., 1996) and was also replicated for the German version (Büssing \& Glaser, 1998). Vanajan et al. (2020) reported sufficient strong internal consistencies of the three dimensions of the MBIGS-D with Cronbach's alpha $=0.86$ (emotional exhaustion), Cronbach's alpha $=0.85$ (cynicism) and Cronbach's alpha $=0.84$ (personal accomplishments).

\section{Perceived Stress Questionnaire (PSQ)}

We applied the short version of the German Perceived Stress Questionnaire (PSQ) by Fliege et al. (2001) which consists of 20 items and which includes the four sub-scales worries, tension, lack of joy and demands. The scale explicitly enables the calculation of an overall score index (cf. for the formula for the overall scores ZPID—Leibniz Institute for Psychology Information, 2009). High values, indicate a high level of perceived stress. The PSQ has a 4-point response format ranging from 1 (= hardly ever) to 4 (= mostly). Sufficient high internal consistency of Cronbach's alpha $>0.80$. was observed for the Perceived Stress Questionnaire (PSQ) by Fliege et al. (2001). The PSQ enables the calculation of four sub-scales and the calculation of an overall index (Ziser et al., 2019). The one dimensional model as used in the current study showed strong internal consistency of Cronbach's alpha $=0.95$ (cf. Vanajan et al, 2020).

\section{Self-Efficacy Scale (SES)}

For measuring self-efficacy (Bandura, 1977) we used the German self-efficacy scale developed by Schwarzer and Jerusalem (1999) which consists of 10 items and which has a 4-point response format ranging from 1 (= not at all true) to 4 (= exactly true). Schwarzer and Jerusalem reported an internal consistency of Cronbach's Alpha between Cronbach's alpha $=0.78$ and Cronbach's alpha $=0.79$ and they confirmed the one-dimensional factor by a confirmatory factor analysis (CFA). 
Fig. 1 Parallel mediator model of deviation from negative time perspective (DNTP) on burnout with perceived stress (PSQ) and self-efficacy (SE) as mediators

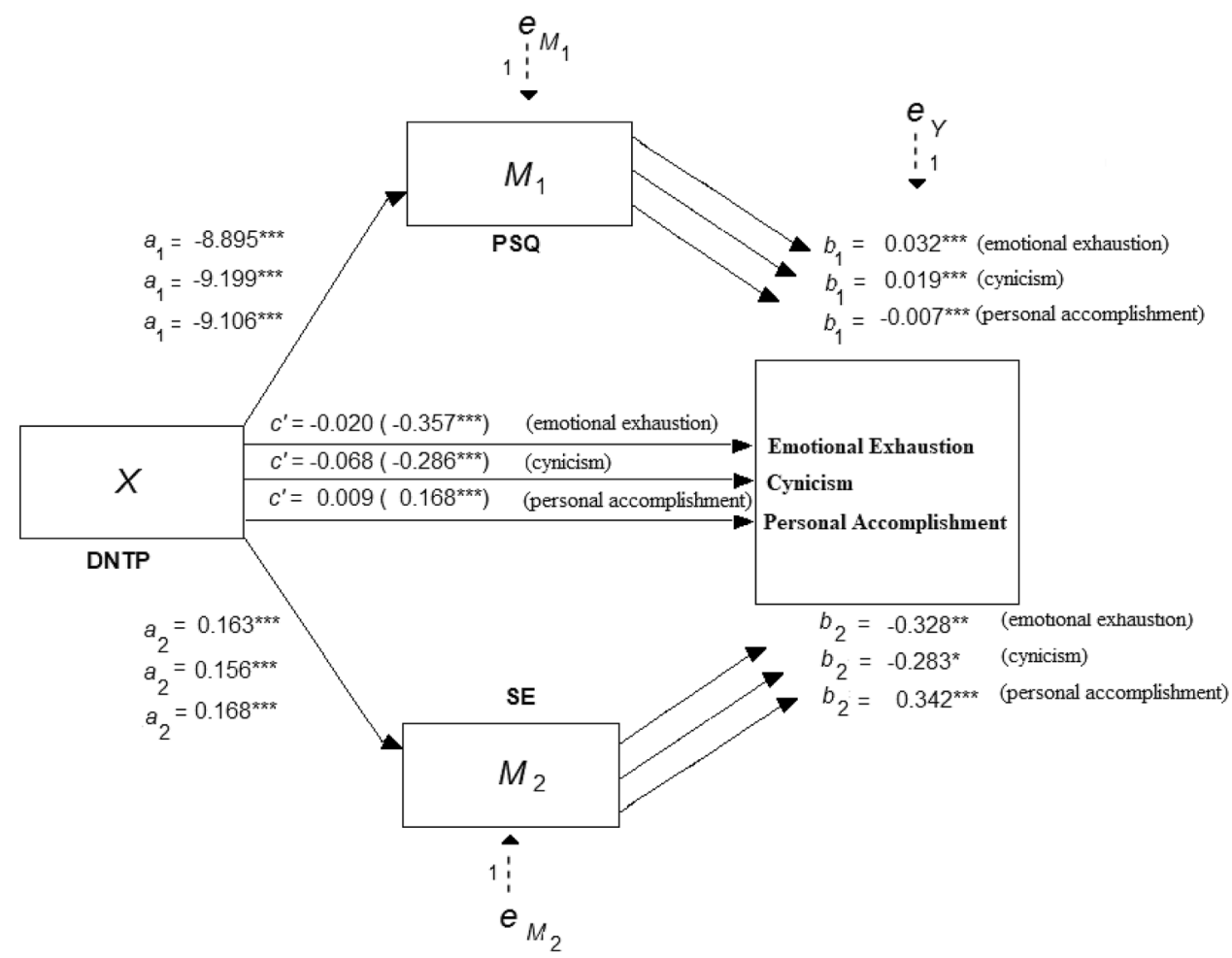

\section{Results}

First, we conducted a correlational analysis between the individual TP's, DBTP, DNTP and all three components of burnout, to test the hypothesized associations between Time Perspectives and burnout. All correlational coefficients together with the means and standard deviations of all measured variables are displayed in Table 1.

As assumed, we observed for Past-Negative TP significant positive associations with emotional exhaustion and cynicism and a negative association with personal accomplishments. Also in line with our hypothesis, Past-Positive showed a reversed significant pattern, specifically negative associations with emotional exhaustion and cynicism, as well as a positive association with personal accomplishments. For Present-Hedonistic and Present-Fatalistic, only the correlation with cynicism reached significance (Present-Hedonistic at the 0.05-level and Present-Fatalistic at the 0.01-level). Future showed one significant negative association with cynicism and one significant positive association with personal accomplishments.

The correlation pattern of the DNTP confirmed our hypothesis: as predicted, we observed for DNTP significant negative associations with emotional exhaustion and cynicism, and a significant positive association with personal accomplishment.

We assume that the overall configuration is decisive (cf. Boniwell and Zimbardo, 2004) and thus, all five TPs contribute, to some extent, to burnout-proneness.
Furthermore, we concluded that the DNTP is more relevant for burnout than the DBTP. We argue that, for preventing the burnout symptomatic, the distance from a negative assumed Time Perspective overall configuration is more relevant than the question of how far the overall configuration is from an optimal assumed Time Perspective configuration (Balanced Time Perspective).

Next, we conducted a mediator analysis for all three burnout dimensions with DNTP as an independent variable and perceived stress and self-efficacy as mediators in a parallel mediator model (cf. Fig. 1 and Table 2). We tested these models by applying the process-macro by Hayes (2013) for SPSS 24 with 5000 bootstraps. First, as assumed, the negative influence of the DNTP on the presumed mediator perceived stress $\left(\mathrm{a}_{1}=-8.895 ; p<0.001\right.$, with emotional exhaustion as a dependent variable; $\mathrm{a}_{1}=-9.199 ; p<0.001$, with cynicism, and $\mathrm{a}_{1}=-9.100$; $p<0.001$, with personal accomplishments) and the positive influence on the presumed mediator self-efficacy $\left(\mathrm{a}_{2}=0.163 ; p<0.001 ; \mathrm{a}_{2}=0.156 ; p<0.001 ; \mathrm{a}_{2}=0.168\right.$; $p<0.001)$ were both significant for all three models, including each of the three burnout dimensions. In summary, those scoring high in DNTP displayed reduced perceived stress levels and higher levels of self-efficacy (cf. Fig. 1 and Table 2).

We observed significant influences of perceived stress $\left(b_{1}=0.032 ; p<0.001\right)$ and self-efficacy $\left(b_{2}=-0.328\right.$; $p=0.009$ ) on emotional exhaustion in the predicted direction. That is, perceived stress leads to higher 
Table 2 Regressions Coefficients, Standard Errors and Model Summary Information for the Presumed Deviation from Negative Time Perspective (DNTP) Influence Parallel Mediator Model with the
Mediators Perceived Stress (PSQ) and Self-efficacy (SE) on the Burnout Dimensions Emotional Exhaustion, Cynicism and Personal Accomplishment

\begin{tabular}{|c|c|c|c|c|c|c|c|c|c|c|c|}
\hline \multirow[t]{2}{*}{ Predictor } & \multicolumn{3}{|l|}{$M_{1}(\mathrm{PS})$} & & \multicolumn{3}{|l|}{$M_{2}(\mathrm{SE})$} & & \multicolumn{3}{|l|}{$Y$ (Burnout) } \\
\hline & Coeff & $S E$ & $p$ & & Coeff & $S E$ & $p$ & & Coeff & $S E$ & $p$ \\
\hline \multicolumn{12}{|c|}{$Y$ (Emotional exhaustion) } \\
\hline$X(\mathrm{DNTP}) a_{1}$ & -8.895 & 1.225 & $<.001$ & $\mathrm{a}_{2}$ & 0.163 & 0.030 & $<.001$ & $c$ & -0.020 & 0.069 & .776 \\
\hline$M_{1}(\mathrm{PS})$ & - & - & - & & - & - & - & $b_{1}$ & 0.032 & 0.003 & $<.001$ \\
\hline$M_{2}(\mathrm{SE})$ & - & - & - & & - & - & - & $\mathrm{b}_{2}$ & -0.328 & 0.124 & .009 \\
\hline & $R^{2}=0.150$ & & & & $R^{2}=0.090$ & & & & $R^{2}=0.150$ & & \\
\hline & $\begin{array}{l}F(1,300)=52.74 \\
\quad p<.001\end{array}$ & & & & $F(1,300)=29.57, p<.001$ & & & & $\begin{array}{l}F(3,298)=52.74 \\
\quad p<.001\end{array}$ & & \\
\hline \multicolumn{12}{|l|}{$Y($ Cynicism $)$} \\
\hline$X$ (DNTP) $a_{1}$ & -9.199 & 1.229 & $<.001$ & $a_{2}$ & 0.156 & 0.030 & $<.001$ & $c$ & -0.068 & 0.072 & 349 \\
\hline$M_{1}(\mathrm{PS})$ & - & - & - & & - & - & - & $b_{1}$ & 0.019 & 0.003 & $<.001$ \\
\hline$M_{2}(\mathrm{SE})$ & - & - & - & & - & - & - & $b_{2}$ & -0.283 & 0.128 & .028 \\
\hline & $R^{2}=0.155$ & & & & $R^{2}=0.080$ & & & & $R^{2}=0.188$ & & \\
\hline & $\begin{array}{l}F(1,306)=55.99 \\
\quad p<.001\end{array}$ & & & & $F(1,306)=26.71, p<.001$ & & & & $\begin{array}{l}F(3,304)=23.51 \\
\quad p<.001\end{array}$ & & \\
\hline \multicolumn{12}{|c|}{$Y$ (Personal accomplishment) } \\
\hline$X(\mathrm{DNTP}) a_{1}$ & -9.106 & 1.253 & $<.001$ & $a_{2}$ & 0.168 & 0.031 & $<.001$ & $c \cdot$ & 0.009 & 0.045 & .839 \\
\hline$M_{1}(\mathrm{PS})$ & - & - & - & & - & - & - & $b_{1}$ & -0.007 & 0.002 & $<.001$ \\
\hline \multirow[t]{3}{*}{$M_{2}(\mathrm{SE})$} & - & - & - & & - & - & - & $b_{2}$ & 0.342 & 0.079 & $<.001$ \\
\hline & $R^{2}=0.150$ & & & & $R^{2}=0.090$ & & & & $R^{2}=0.155$ & & \\
\hline & $\begin{array}{l}F(1,299)=52.00 \\
\quad p<.001\end{array}$ & & & & $F(1,299)=29.44, p<.001$ & & & & $\begin{array}{l}F(3,297)=18.18 \\
\quad p<.001\end{array}$ & & \\
\hline
\end{tabular}

$D N T P$ deviation from negative time perspective, $P S$ perceived stress, $S E$ self efficacy

emotional exhaustion, while self-efficacy reduces emotional exhaustion.

The indirect effects of DNTP on emotional exhaustion mediated by perceived stress reached significance $(-0.283$ with $95 \%$ CI $[-0.388,-0.195])$, as well as the indirect effect mediated by self-efficacy $(-0.054$ with $95 \%$ CI $[-0.107,-0.010])$. Finally, the observed direct significant influence of DNTP ( $c=-0.357 ; p<0.001$ ) on emotional exhaustion remained non-significant, when both mediators were introduced $\left(c^{\prime}=-0.020 ; p=0.776\right)$, indicating a total mediation.

For the second dimension of cynicism, the results indicated, as predicted, a significant influence of the mediators perceived stress $\left(b_{1}=0.019 ; p<0.001\right)$ and self-efficacy $\left(b_{2}=-0.283 ; p=0.028\right)$ on cynicism. Again a complete mediation was observed: first, the indirect effects of DNTP on cynicism mediated by perceived stress $(-0.174$ with 95\% CI [-0.250, -0.104] and mediated by self-efficacy: 0.044 with $95 \%$ CI $[-0.093,-0.002]$ ) reached significance. Second the direct influence of DNTP on cynicism (c $=-0.286 ; p<0.001)$ disappeared, when both mediators were introduced $\left(c^{\prime}=0.068 ; p=0.349\right)$.

For the third dimension of personal accomplishment, again perceived stress $\left(b_{1}=-0.007 ; p<0.001\right)$ and self- efficacy $\left(b_{2}=0.342 ; p<0.001\right)$ significantly influenced personal accomplishment in the reversed direction. The predicted mediator-model was again confirmed as indicated by significant indirect effects mediated by perceived stress $(0.064$ with $95 \%$ CI $[0.029,0.101])$ and self-efficacy $(0.057$ with $95 \%$ CI $[0.028,0.092])$. The direct effect of DNTP $(\mathrm{c}=0.168 ; \mathrm{p}<0.001)$ again disappeared $\left(\mathrm{c}^{\prime}=\right.$ $0.009 ; p=0.839)$. In sum, the influence of DNTP on all three burnout-dimensions was completely mediated as predicted in our model.

As a next step, we conducted additional analysis with age as covariate. Several studies have reported differences and changes in TP across different ages (Laureiro-Martinez et al., 2017; Pethtel et al., 2018; Simons et al., 2018). In our sample, we have an age-biased sample with a younger sample compared to representative data in Germany, which shows that older ages prevail in the health care staff (D_Statis, 2019). On the other hand, a meta-analytic study by Gómez-Urquiza et al. (2017) came to the conclusion that a younger age is an important risk-factor for emotional exhaustion, cynicism, and to a somewhat lower degree for lowered personal accomplishments. The main focus of our study is the association of TPs to the burnout proneness. Consequently, a younger sample with a higher burnout risk 
may be adequate for testing individual differences in TPs as a cause of burnout. Nonetheless, due to the above assumed changes in TPs across the life span, we had an additional look on possible limitations of our study because of an over-representation of younger professionals. Thus, we conducted some additional analysis: We analyzed the role of age for the tested model by conducting an additional mediator analysis, which includes age as covariate. As in the main analysis, we again applied the process-macro by Hayes (2013) for SPSS 24 with 5000 bootstraps. The first analysis, which included the overall burnout index, revealed the same pattern as in the original analysis: the effect of DNTP on perceived stress $\left(a_{1}=-9.310\right.$; $p<0.001)$ and on self-efficacy $\left(\mathrm{a}_{2}=0.151 ; \mathrm{p}<0.001\right)$ both reached significance. Also the influence of perceived stress $\left(b_{1}=0.018 ; p<0.001\right)$ and the one of self-efficacy $\left(b_{2}=-0.337 ; p<0.001\right)$ on the overall burnout index both remained significant. The observed direct effect of DNTP on the overall burnout index $(\mathrm{c}=-0.240$; $p<0.001)$ disappeared again in the model with the covariate age, when both mediators were introduced into the model $\left(\mathrm{c}^{\prime}=-0.018 ; p=0.714\right)$. Correspondingly, all indirect effects reached significance (Indirect effect ${ }_{\text {TOTAL- }}$ $=-0.222$ with $95 \%$ CI $[-0.292,-0.157] ;$ Indirect effect $_{\text {PERCEIVED STRESS }}=-0.171$ with $95 \%$ CI $[-0.233$; $-0.114]$; Indirect effect SELF-EFFICACY $=-0.051$ with $95 \%$ CI $[-0.090 ;-0.021])$. Further, the covariate age reached significance $(p=0.033)$. This pattern of a total mediation of the influence of DNTP on burnout by perceived stress and by self-efficacy remained stable when repeating the analysis with the three burnout dimensions of emotional exhaustion $\quad\left(\mathrm{c}=-0.356 ; \quad p<0.001 ; \quad \mathrm{c}^{\prime}=-0.004\right.$; $p=0.952), \quad$ cynicism $\quad\left(\mathrm{c}=-0.264 ; \quad p<0.001 ; \quad \mathrm{c}^{\prime}=\right.$ $-0.037 ; p=0.620)$ and personal accomplishments-reversed $\left(\mathrm{c}=-0.126 ; p=0.005 ; \mathrm{c}^{\prime}=-0.009 ; p=0.844\right)$. All indirect effects for emotional exhaustion reached significance (Indirect effect TOTAL $=-0.352$ with $95 \%$ CI $[-0.471 ;-0.249] ;$ Indirect effect PERCEIVED $_{\text {STRESS- }}$ $=-0.303$ with $95 \%$ CI $[-0.413 ;-0.207] ;$ Indirect effect $_{\text {SELF-EFFICACY }}=-0.050$ with $95 \%$ CI $[-0.104$; $-0.009])$. For cynicism, the total and the one of perceived stress reached significance. The one of self-efficacy was not significant (Indirect effect TOTAL $=-0.227$ with $95 \%$ CI $[-0.317 ;-0.147]$; Indirect effect PERCEIVED STRESS- $_{\text {PED }}$ $=-0.186$ with $95 \%$ CI $[-0.270 ;-0.114] ;$ Indirect effect $_{\text {SELF-EFFICACY }}=-0.041$ with $95 \%$ CI $[-0.088$; 0.004]). For personal accomplishments (reversed), all indirect effects reached significance again (Indirect effect $_{\mathrm{TOTAL}}=-0.117$ with $95 \%$ CI $[-0.162,-0.072]$; Indirect effect $t_{\text {PERCEIVED STRESS }}=-0.061$ with $95 \%$ CI $[-0.100 ;-0.025] ;$ Indirect effect SELF-EFFICACY $=-0.055$ with $95 \%$ CI $[-0.087,-0.026])$. Thus, both mediator effects were confirmed with the exception that, in the case of cynicism, the indirect effect was mediated only by perceived stress and not by self-efficacy. The covariate age reached significance in the analysis for cynicism ( $p=0.024$ ) but not for the one for emotional exhaustion $(p=0.378)$ and for personal accomplishments reversed $(p=0.368)$. To summarize, these additional analyses of the role of age bring us to the conclusion that age is an important factor which needs to be addressed in future studies. On the other hand, our main results do not seem to be affected by the age-biased structure of the current sample.

\section{Discussion}

The influence of TPs on burnout, was supported in the current study. We observed reducing significant effects of the DNTP on all three burnout dimensions. Thus, the basic assumptions were confirmed, and we were further able to identify an important underlying mechanism of the influence of TPs on burnout by observing that the DNTP is predominantly fully mediated via the mediators of perceived stress and self-efficacy for emotional exhaustion, cynicism and personal accomplishment. This mediation model was shown without exception for all three burnout dimensions. The importance of DNTP arises according to our argumentation because of its trait-like character, whereas perceived stress, as well as self-efficacy, showed more situational fluctuations.

Regarding the single TPs, we observed that associations of both past dimensions Past-Negative and Past-Positive were each significant in the predicted direction throughout all three burnout dimensions. For the other TPs, the observations were more mixed: The presumed positive association of Present-Fatalistic and burnout was only confirmed for cynicism. Present-Hedonistic showed an unexpected significant positive association with cynicism.

While the overall configuration as operationalized in the current study as DNTP is essential for the influence on burnout, the association of the individual TPs as observed, together with a comparison of the corresponding results of other studies, may deliver helpful insights on the question of the focus of a therapy altering TPs.

The comparison of our results of the individual TPs with those of the studies by Akirmak and Ayla (2021) and by Meidani et al. (2019) with respect to the relationship between Past-Negative and Past-Positive orientations and burnout shows significance as predicted.

Moreover, we observed only one predicted positive association of Present-Fatalistic TP with cynicism. Akirmak and Ayla (2021) also reported a positive association with the general burnout overall dimension, whereas Meidani et al. (2019) reported associations with all three 
sub-dimensions of burnout. In the case of Present-Hedonism, Akirmak and Ayla (2021) reported no significant association. Meidani et al. (2019) reported a negative association with emotional exhaustion and cynicism, as well as a positive association with personal accomplishment. In our study, one unexpected result was the observation of only one significant positive association of Present-Hedonistic TP with cynicism.

Finally, for the Future dimension, we observed a significant negative association with the two first dimensions of burnout and a positive association with personal accomplishment. These results, however, are contradictory to our prior hypotheses of a reversed relationship between Future TP and burnout. This was based on Boniwell and Zimbardo (2004), who stated that a possible drawback of high Future orientation may be the enhanced risk for developing burnout symptoms. The results of our study, however, did not support this assumption. We initially assumed that a strong Future perspective is indeed a prerequisite for burnout (in particular, if prior work engagement turns into workaholism).

According to the analysis of the individual TPs, we can conclude that the Past-Negative and Past-Positive dimensions are apparently the most essential ones for potential therapy in all three components of burnout in the case of health care professionals. Furthermore, a low PresentFatalistic orientation also seems to be negatively associated with burnout, whereas the role of Present-Hedonistic in our study seems to be unclear. Finally, contrary to our initial hypotheses, a high Future dimension was negatively associated with burnout proneness in two out of the three subdimensions. Altogether, our study supports the idea that the therapeutic intervention toward a higher DNTP may be both a straightforward approach to ameliorate symptoms of burnout and a preventive measure to avoid the risk of burnout.

According to the comparison with the other available studies, we have to consider that these studies focused on other professional groups in different cultural settings, such as bank-employees in Turkey (Akirmak \& Ayla, 2021) and teachers in Iran (Meidani et al., 2019). Future research must analyze if differences between the influence of TPs on burnout are observable between different occupational groups, and if our tested underlying mechanism of the mediated influence of DNTP mediated by perceived stress and self-efficacy can be generalized across different occupational and cultural settings. The observed similarities for the individual TPs may be a first hint for a possible generalizability.

\section{Limitations and Future Research}

Our current study has certain limitations. First, the crosssectional design does not allow strict causal testing. Consequently, we suggest the conduction of longitudinal studies, in order to better understand how TP and burnout proneness are related to each other and to further scrutinize our hypotheses. Several authors issued the change of TPs along the life span (Chen et al., 2016a, 2016b; LaureiroMartinez et al., 2017). It is assumed that TPs are developed during socialization, and that during each phase of life, shifts and alterations are possible and can be expected. Thus, it can be assumed that, e.g., organizational factors in the working context influence the TPs in a reversed direction. This addresses another important limitation of the current study that needs to be tested in future research: Are TPs themselves altered by burnout developments as a kind of adaptive reaction?

This may also deliver one possible explanation for the observed negative association of Future TP with burnout: as long as the burnout is low, Future TP could have an inhibiting effect and, as soon as burnout is developed, the Future TP may itself be reduced by this development, resulting in the observed negative association. According to Schaufeli and Buunk (2002), burnout is triggered in development phases, since it can be characterized by a high work-related achievement motivation which predominates in earlier stages, whereas in later stages disillusion and lowered achievement motivation begin to spread.

While the current study does deliver an important mediation model for the influence of TP and Burnout, other variables have not been addressed, such as organizational variables or other variables of personal differences, such as attributional style, differences in resilience, self-control or others. Future research is necessary to include additional variables and constructs that are important for burnout proneness. In our sample, younger health care professionals are overrepresented, while older ones are underrepresented. Thus, another limitation is that our study does not provide much information on older health care staff. The general tested assumption about the influence of TP on burnout as tested in our study are, however, not affected by the age biased sample structure, because younger health care professionals have the tendency to be more at risk of burnout (Gómez-Urquiza et al., 2017; Marchand et al., 2018). Nonetheless, we recommend future studies which should also investigate the observed effects with older samples. 


\section{Conclusion}

Our study has shown that proneness to burnout among health care professionals is associated with TPs. The DBTP showed a positive and the DNTP a negative association throughout all three burnout dimensions, namely emotional exhaustion, cynicism and personal accomplishments (reversed). Most importantly, the conducted parallel mediator model has revealed that the assumed influence of DNTP on all three burnout dimensions is totally mediated by perceived stress and self-efficacy. Thus, our study identified an underlying mechanism on how DNTP is associated with burnout proneness and burnout vulnerability. We are aware that perceived stress and self-efficacy also depend on other variables, but our tested mediation model on the influence of time perspective on burnout, delivers a new explanation of how TPs influence burnout and how altered maladaptive TPs could prevent burnout. As it is in other studies, the current study confirmed the association of TP and burnout. More specifically, the current study showed this association for a highly effected professional group of health care professionals. Further, we identified that the distance from the DNTP is of substantial importance for the burnout proneness. Finally, the study revealed an underlying mechanism of the influence of the DNTP on burnout by showing that this influence is mediated by perceived stress and self-efficacy.

The practical conclusion of our study, together with those conducted with samples from other branches, is that the ZTPI may be used an indicator for burnout vulnerability. TP-based interventions may also be very helpful for preventive purposes. As shown in the study, a high score in Past Negative and a low score in Past Positive TP seems to be particularly problematic. To avoid premature conclusions, we highly recommend follow-up studies and studies with burnout patients. On the other hand, the advantage of using the ZTPI to detect possible risks of developing a burnout symptomatic may be that changes in the ZTPI occur presumably before an individual is aware of specific burnout symptoms. Long-term studies, however, are necessary to test this speculation. Another important practical implication may be the application of the TP-based therapy as developed by Zimbardo et al. (2012) for treating PTSD patients. A skeptical view is expressed by McKay and Cole (2020), when it comes to the use of DNTP and DBTP for therapeutic purposes. Again, further studies with burnout patients would be helpful to scrutinize the observed patterns before testing therapeutic treatments of burnout patients. Together with future research in this domain, this may help clinical psychologists to develop TP-based therapies to cure burnout or to apply TP measurements as an early indicator of being at risk of developing a burnout symptomatology.

Acknowledgements We would like to thank Prof. Dr. Jürgen Glaser (Institute of Psychology, University of Innsbruck, Austria) for his kind permission to use the MBI-GS-D (authorized German versions of the Maslach-Burnout-Inventory) for this research-project. We would also like to thank all involved health-care institutions in the federal state of Rhineland-Pfalz and their representatives: Matthias Frietsch (Vocational School of Nursing, Eisenberg), Timo Siebenborn (Caritas Association for the Diocese of Speyer), Ulrike Lahr (Ecumenical Centre of Social Services, Limburgerhof), Santina Rudolph (St. Marien- and St. Annastift's Hospital of Ludwigshafen) and Monika Dunkmann (School of Nursing at the Clinical Centre of Ludwigshafen). Without their kind permission of data-collection at their institutions the current study could not be realized. We also like to thank Prof. Dr. Karin Kersting (Ludwigshafen University of Business and Society, Germany) who supported us in choosing the adequate participating institutions.

Funding Open Access funding enabled and organized by Projekt DEAL. The authors received no funding for this work.

Availability of Data and Material Data and used scales are available on request from the first author.

Code Availability SPSS statistical software (IBM SPSS Statistics).

\section{Declarations}

Conflict of interest All authors declare that they have no conflict of interest and no competing interests.

Ethical standards All procedures performed in this study were in accordance with the ethical standards of the 1964 Helsinki Declaration and its later amendments or comparable ethical standards. The tools used are simple self report scales and the participation in the study has zero risk involvement. Hence it was not mandatory in our institution to obtain the clearance from Institute Ethics Committee.

Consent to Participate Consent form used.

Consent for Publication The authors jointly consent for the manuscript to be published by the journal.

Open Access This article is licensed under a Creative Commons Attribution 4.0 International License, which permits use, sharing, adaptation, distribution and reproduction in any medium or format, as long as you give appropriate credit to the original author(s) and the source, provide a link to the Creative Commons licence, and indicate if changes were made. The images or other third party material in this article are included in the article's Creative Commons licence, unless indicated otherwise in a credit line to the material. If material is not included in the article's Creative Commons licence and your intended use is not permitted by statutory regulation or exceeds the permitted use, you will need to obtain permission directly from the copyright holder. To view a copy of this licence, visit http://creativecommons.org/licenses/by/4.0/. 


\section{References}

Akirmak, U., \& Ayla, P. (2021). How is time perspective related to burnout and job satisfaction? A conservation of resources perspective. Journal of Personality and Individual Differences. https://doi.org/10.1016/j.paid.2019.109667181109667.

Bakker, A. B., van der Zee, K. I., Lewig, K. A., \& Dollard, M. F. (2006). The relationship between the big five personality factors and burnout: A study among volunteer counselors. The Journal of Social Psychology, 146(1), 31-50. https://doi.org/10.3200/SOCP.146.1.31-50

Bandura, A. (1977). Self-efficacy: Toward a unifying theory of behavioral change. Psychological Review, 84(2), 191-215. https://doi.org/10.1037/0033-295X.84.2.191

Bernotaite, L., \& Malinauskiene, V. (2017). Workplace bullying and mental health among teachers in relation to psychosocial job characteristics and burnout. International Journal of Occupational Medicine and Environmental Health, 30(4), 629-640. https://doi.org/10.13075/ijomeh.1896.00943.

Blomgren, A.-S., Svahn, K., Åström, E., \& Rönnlund, M. (2016). Coping strategies in late adolescence: Relationships to parental attachment and time perspective. The Journal of Genetic $\begin{array}{lrl}\text { Psychology, } & 177(3), & 85-96 .\end{array}$ https://doi.org/10.1080/00221325.2016.1178101

Bolotova, A. K., \& Hachaturova, M. R. (2013). The role of time perspective in coping behavior. Psychology in Russia: State of the Art, 6(3), 120-131.

Boniwell, I., \& Zimbardo, P. G. (2004). Balancing one's time perspective in pursuit of optimal functioning. In P. A. Linley, \& S. Joseph (Eds.), Positive psychology in practice (pp. 165-178). Wiley. https://doi.org/10.1002/9780470939338.ch22.

Boyd, J. N., \& Zimbardo, P. G. (2005). Time perspectives, health, and risk taking. In A. Strathman \& J. Joireman (Eds.), Understanding behavior in the context of time: Theory, research, and applications (pp. 85-108). Lawrence Erlbaum Associates Publishers.

Bria, M., Baban, A., \& Dumitrascu, D. L. (2012). Systematic review of burnout risk factors among European healthcare professionals. Cognition, brain, behavior: An interdisciplinary journal, 16(3), 423-452.

Bridgeman, P. J., Bridgeman, M. B., \& Barone, J. (2018). Burnout syndrome among healthcare professionals. American Journal of Health-System Pharmacy, 75(3), 147-152. https://doi.org/10.2146/ajhp170460

Büssing, A., \& Glaser, J. (1998). Managerial stress und burnout. A collaborative international Study (CISMS). The German translation (Report Nr. 44). Technical University, Chair of Psychology.

Chen, T., Liu, L., Cui, J., Chen, X., Wang, J., Zhang, Y., Wang, Y., Li, X., Neumann, D. L., Shum, D. H. K., Wang, Y., \& Chan, R. C. K. (2016b). Present-fatalistic time perspective and life satisfaction: The moderating role of age. Personality and Individual Differences, 99, 161-165. https://doi.org/10.1016/j.paid.2016.05.017

Chen, T., Liu, L., Cui, J., Chen, X., \& Wang, Y. (2016a). Developmental trajectory of time perspective: From children to older adults. PsyCh Journal, 5(4), 245-255. https://doi.org/10.1002/pchj.140

Credé, M., Harms, P., Niehorster, S., \& Gaye-Valentine, A. (2012). An evaluation of the consequences of using short measures of the Big Five personality traits. Journal of Personality and Social Psychology, 102, 874-888. https://doi.org/10.1037/a0027403

D_Statis. (2019). Statistisches Bundesamt. Retrieved from https://www.destatis.de/EN/Themes/Society-Environment/ Health/Health-Personnel/_node.html;jsessionid= 9901CF7BA3B1AD26970E8305CDCFE487.live741.
Danner, D., Treiber, L., \& Bosnjak, M. (2019). Development and psychometric evaluation of a short version of the Time Perspective Inventory. European Journal of Psychological Assessment, 35(2), 172-181. https://doi.org/10.1027/1015-5759/a000382

Detaille, S., Reig-Botella, A., Clemente, M., López-Golpe, J., \& De Lange, A. (2020). Burnout and time perspective of blue-collar workers at the shipyard. International Journal of Environmental Research and Public Health, 17(18), 6905. https://doi.org/10.3390/ijerph17186905

Dunkel, C. S., \& Weber, J. L. (2010). Using three levels of personality to predict time perspective. Current Psychology, 29(2), 95-103. https://doi.org/10.1007/s12144-010-9074-x

Epel, E. S., Bandura, A., \& Zimbardo, P. G. (1999). Escaping homelessness: The influences of self-efficacy and time perspective on coping with homelessness. Journal of Applied Social Psychology, 29(3), 575-596. https://doi.org/10.1111/j.1559-1816.1999.tb01402.x

Fliege, H., Rose, M., Arck, P., Levenstein, S., Burghard, F., \& Klapp, B. F. (2001). Validierung des "Perceived Stress Questionnaire" (PSQ) an einer deutschen Stichprobe [Validation of the "Perceived Stress Questionnaire“ (PSQ) for a German sample]. Diagnostica, $\quad 47(3), \quad 142-152$. https://doi.org/10.1026//0012-1924.47.3.142

Gómez-Urquiza, J. L., Vargas, C., De la Fuente, E. I., FernándezCastillo, R., \& Cañadas-De la Fuente, G. A. (2017). Age as a risk factor for burnout syndrome in nursing professionals: A metaanalytic study. Research in Nursing Health, 40(2), 99-110. https://doi.org/10.1002/nur.21774

Hayes, A. F. (2013). Introduction to mediation, moderation, and conditional process analysis - A regression-based approach. The Guilford Press.

Kairys, A., \& Liniauskaite, A. (2015). Time perspective and personality. In M. Stolarski, N. Fieulaine, \& W. van Beek (Eds.), Time perspective theory; review, research and application (pp. 99-113). Springer. https://doi.org/10.1007/978-3-319-07368-2.

Kairys, A., Liniauskaite, A., Bagdonas, A., \& Pakalniškienè, V. (2017). Balanced time perspective: Many questions and some answers. In A. Kostić \& D. Chadee (Eds.), Time perspectivetheory and practice (pp. 97-115). Palgrave Macmillan.

Kane, L. (2019). Medscape national physician burnout, depression \& suicide report 2019 Medscape. Retrieved from https://www.medscape.com/slideshow/2019-lifestyle-burnoutdepression-6011056? faf $=1 \# 1$.

Kokkinos, C. M. (2007). Job stressors, personality and burnout in primary school teachers. The British Psychological Society, 77(1), 229-243. https://doi.org/10.1348/000709905X90344

Langelaan, S., Bakker, A. B., van Doornen, L. J. P., \& Schaufeli, W. B. (2006). Burnout and work engagement: Do individual differences make a difference? Personality and Individual Differences, $\quad 40, \quad 521-532$. https://doi.org/10.1016/j.paid.2005.07.009

Laureiro-Martinez, D., Trujillo, C. A., \& Unda, J. (2017). Time perspective and age: A review of age associated differences. $\begin{array}{lll}\text { Frontiers in } & \text { Psychology, }\end{array}$ https://doi.org/10.3389/fpsyg.2017.00101.

Lewin, K. (1936). Principles of topological psychology. McGrawHill. https://doi.org/10.1037/10019-000

Lloyd, C., King, R., \& Chenoweth, L. (2002). Social work, stress and burnout: A review. Journal of Mental Health, 11(3), 255-265. https://doi.org/10.1080/09638230020023642.

Luszczynska, A., Gutiérrez-Doña, B., \& Schwarzer, R. (2005). General self-efficacy in various domains of human functioning: Evidence from five countries. International Journal of Psychology, 40(2), 80-89. https://doi.org/10.1080/00207590444000041 
Marchand, A., Blanc, M.-E., \& Beauregard, N. (2018). Do age and gender contribute to workers' burnout symptoms? Occupational Medicine, 68(6), 405-411. https://doi.org/10.1093/occmed/kqy088

Maslach, C., \& Leiter, M. P. (2000). The truth about burnout: How organisations cause personal stress and what to about it. Jossey Bass-A Wiley Brand.

McKay, M. T., \& Cole, J. C. (2020). The relationship between balanced and negative time perspectives, and symptoms of anxiety and depression. Psychiatry Research, 293, 113383. https://doi.org/10.1016/j.psychres.2020.113383

Meidani, E. N., Pishghadam, R., \& Shakeebaee, G. (2019). The role of time perspectives in Language Teachers' Burnout. Current Psychology. https://doi.org/10.1007/s12144-019-00456-x

Messias, E., Gathright, M. M., Freeman, E. S., Flynn, V., Atkinson, T., Thrush, C. R., Clardy, J. A., \& Thapa, P. (2019). Differences in burnout prevalence between clinical professionals and biomedical scientists in an academic medical centre: A crosssectional survey. British Medical Journal Open, 9(2), e023506. https://doi.org/10.1136/bmjopen-2018-023506

Moss, M., Good, V. S., Gozal, D., Kleinpell, R., \& Sessler, C. N. (2016). An official critical care societies collaborative statement: Burnout syndrome in critical care healthcare professionals: A call for action. Critical Care Medicine, 44(7), 1414-1421. https://doi.org/10.1097/CCM.0000000000001885

Nuttin, J. (1985). Future time perspective and motivation. Leuven University Press and Lawrence Erlbaum Associates.

Olivera-Figueroa, L. A., Juster, R.-P., Morin-Major, J. K., Marin, M. F., \& Lupien, S. J. (2015). A time to be stressed? Time perspectives and cortisol dynamics among healthy adults. Biological Psychology, 111, 90-99. https://doi.org/10.1016/j.biopsycho.2015.09.002

Oyanadel, C., \& Buela-Casal, G. (2017). Time perception and health: The influence of balanced time perspective profile (BTP) and the negative time perspective profile (NTP) on physical and mental health. Revista Argentina de Clínica Psicológica, 26(3), 296-306. https://doi.org/10.24205/03276716.2017.1034.

Oyanadel, C., \& Buela-Casal, G. (2014). Time perception and psychopathology: Influence of time perspective on quality of life of severe mental illness. Actas Españolas De Psiquiatría, 42(3), 99-107.

Oyanadel, C., Buela-Casal, G., Araya, T., Olivares, C., \& Vega, H. (2014). Time perception: Results of a brief group intervention to change time perspective profiles. Suma Psicologica, 21(1), 1-7.

Papastamatelou, J., \& Unger, A. (2018). Differences in burnout proneness depend on time perspective-evidence from an occupational sample of industrial employees and MBA-students. Dialogues in Clinical Neuroscience \& Mental Health, 1, 52-57. https://doi.org/10.26386/obrela.v1i1.8.

Papastamatelou, J., Unger, A., Giotakos, O., \& Athanasiadou, F. (2015). Is time perspective a predictor of anxiety and perceived stress? Some preliminary results from Greece. Psychological Studies, $60(4)$,

468-477. https://doi.org/10.1007/s12646-015-0342-6

Pethtel, O. L., Moist, M., \& Baker, S. (2018). Time perspective and psychological well-being in younger and older adults. Journal of Positive School Psychology, 2(1), 45-63. https://www.journal.ppw.com/index.php/JPPW/article/view/51.

Pruszczak, D., Stolarski, M., \& Jankowski, K. S. (2017). Chronotype and time metaphors: Morning-types conceive time as more friendly and less hostile. Biological Rhythm Research, 49(3), 431-441. https://doi.org/10.1080/09291016.2017.1368215

Rammstedt, B., \& John, O. P. (2007). Measuring personality in one minute or less: A 10-item short version of the Big Five Inventory in English and German. Journal of Research in Personality, 41, 203-212. https://doi.org/10.1016/j.jrp.2006.02.001
Reig-Botella, A., Detaille, S., Clemente, M., López-Golpe, J., \& de Lange, A. (2021). Sustainability Time perspective and the risk of developing burnout: An empirical study among different bluecollar workers in Spain. Sustainability, 13, 3271. https://doi.org/10.3390/su13063271

Schaufeli, W. B., Leiter, M. P., Maslach, C., \& Jackson, S. E. (1996). Maslach burnout inventory-general survey. In C. Maslach, S. E. Jackson, \& M. P. Leiter (Eds.), The Maslach burnout inventory: Test manual (3rd ed., pp. 22-26). Consulting Psychologists Press.

Schaufeli, W. B. (2017). Burnout: A short socio-cultural history. In S. Neckel, A. K. Schaffner, \& G. Wagner (Eds.), Burnout, fatigue, exhaustion: An interdisciplinary perspective on a modern affliction (pp. 105-127). Palgrave Macmillan. https://doi.org/10.1007/978-3-319-52887-8_5.

Schaufeli, W. B., \& Buunk, B. (2002). Professional burnout. In M. J. Schabracq, J. A. M. Winnubst, \& C. L. Cooper (Eds.), The handbook of work and health psychology (pp. 311-346). Wiley.

Schwarzer, R., \& Jerusalem, M. (1999). Skalen zur Erfassung von Lehrer- und Schülermerkmalen. [Scales for the assessment of teacher and student characteristics]. Freie Universität Berlin.

Schwarzer, R., \& Hallum, S. (2008). Perceived teacher self-efficacy as a predictor of job stress and burnout: Mediation analyses. Applied Psychology: An International Review, 57(1), 152-171. https://doi.org/10.1111/j.1464-0597.2008.00359.x

Shipp, A. J., Edwards, J. R., \& Lambert, L. S. (2009). Conceptualization and measurement of temporal focus: The subjective experience of the past, present, and future. Organizational Behavior and Human Decision Processes, 110, 1-22. https://doi.org/10.1016/j.obhdp.2009.05.001

Simons, M., Peeters, S., Janssens, M., Lataster, J., \& Jacobs, N. (2018). Does age make a difference? Age as moderator in the association between time perspective and happiness. Journal of Happiness $\quad$ Studies, $19, \quad 57-67$. https://doi.org/10.1007/s10902-016-9806-1

Skaalvik, E. M., \& Skaalvik, S. (2010). Teacher self-efficacy and teacher burnout: A study of relations. Teaching and Teacher Education, 26(4), 1059-1069. https://doi.org/10.1016/j.tate.2009.11.001

Stolarski, M., Ledzińska, M., \& Matthews, G. (2013). Morning is tomorrow, evening is today: Relationships between chronotype and time perspective. Biological Rhythm Research, 44(2). https://doi.org/10.1080/09291016.2012.656248.

Stolarski, M., Wiberg, B., \& Osin, E. (2015). Assessing temporal harmony: The issue of a balanced time perspective. In M. Stolarski, N. Fieulaine, \& W. van Beek (Eds.), Time perspective theory: Review, research and application (pp. 57-71). Springer. https://doi.org/10.1007/978-3-319-07368-2.

Stolarski, M., Fieulaine, N., \& Zimbardo, P. G. (2018). Putting time in a wider perspective: The past, the present, and the future of time perspective theory. In V. Zeigler-Hill, \& Todd Shackelford (Eds.), The SAGE handbook of personality and individual differences (pp. 592-628). https://doi.org/10.4135/9781526451163.n28.

Stolarski, M., Bitner, J., \& Zimbardo, P. G. (2011). Time perspective, emotional intelligence and discounting of delayed awards. Time $\begin{array}{llll}\text { \&amp; } & \text { Society, } & \text { 20(3), }\end{array}$ https://doi.org/10.1177/0961463X11414296

Stolarski, M., Matthews, G., Postek, S., Zimbardo, P. G., \& Bitner, J. (2013b). How we feel is a matter of time: Relationships between time perspectives and mood. Journal of Happiness Studies, 15(5), 809-827. https://doi.org/10.1007/s10902-013-9450-y

Stolarski, M., Vowinckel, J., Jankowski, K. S., \& Zajenkowski, M. (2016). Mind the balance, be contented: Balanced time perspective mediates the relationship between mindfulness and life 
satisfaction. Personality and Individual Differences, 93, 27-31. https://doi.org/10.1016/j.paid.2015.09.039

Strathman, A., Gleicher, F., Boninger, D. S., \& Edwards, C. S. (1994). The consideration of future consequences: Weighing immediate and distant outcomes of behavior. Journal of Personality and $\begin{array}{lll}\text { Social Psychology, } & 66(4), & 742-752 .\end{array}$ https://doi.org/10.1037/0022-3514.66.4.742

Svenson, O., \& Maule, A. J. (Eds.). (1993). Time pressure and stress in human judgment and decision making https://doi.org/10.1007/978-1-4757-6846-6.

Talavera-Velasco, B., Luceño-Moreno, L., Martín-García, J., \& García-Albuerne, Y. (2018). Psychosocial risk factors, burnout and hardy personality as variables associated with mental health in police officers. Frontiers in Psychology, 9:1478. https:// https://doi.org/10.3389/fpsyg.2018.01478.

van Beek, W., Berghuis, H., Kerkhof, A., \& Beekman, A. (2011). Time perspective, personality and psychopathology: Zimbardo's time perspective inventory in psychiatry. Time \&amp; Society, 20(3), 364-374. https://doi.org/10.1177/0961463X10373960

Vanajan, A., Stier-Jarmer, M., Ivandic, I., Schuh, A., \& Sabariego, C. (2020). Can participants' characteristics predict benefit from a multimodal burnout prevention program? Secondary analysis of a randomized controlled trial conducted in Germany. Behavioral Medicine, $46(2)$,

120-129. https://doi.org/10.1080/08964289.2019.1594671

Vowinckel, J. C., Westerhof, G. J., \& Bohlmeijer, E. T. (2015). Flourishing in the now: Initial validation of a present-eudaimonic time perspective scale. Time \&amp; Society, 1(24), 40-52. https://doi.org/10.1177/0961463X15577277

Witowska, J., Zajenkowski, M., \& Wittmann, M. (2020). Integration of balanced time perspective and time perception: The role of executive control and neuroticism. Personality and Individual Differences, 163 ,

$1-5$. https://doi.org/10.1016/j.paid.2020.110061

Wittmann, M. (2013). The inner sense of time: How the brain creates a representation of duration. Nature Reviews Neuroscience, 14, 217-223. https://doi.org/10.1038/nrn345210.1038/nrn3452

Zajenkowski, M., Stolarski, M., Maciantowicz, O., Malesza, M., \& Witowska, J. (2016). Time to be smart: Uncovering a complex interplay between intelligence and time perspectives. Intelligence, 58(1-9). https://doi.org/10.1016/j.intell.2016.06.002.

Zakay, D., \& Block, R. A. (1997). Temporal cognition. Current Directions in Psychological Science, 6(1), 12-16. https://doi.org/10.1111/1467-8721.ep11512604

Zaleski, Z., \& Przepiórka, A. (2015). Goals need time perspective to be achieved. In M. Stolarski, N. Fieulaine, \& W. van Beek (Eds.), Time perspective theory: Review, research and application (pp. 323-335). https://doi.org/10.1007/978-3-319-07368-2.

Zaleski, Z. (1996). Future anxiety: Concept, measurement, and preliminary research. Personality and Individual Differences, 21(2), 165-174. https://doi.org/10.1016/0191-8869(96)00070-0

Zhang, J. W., \& Howell, R. T. (2011). Do time perspectives predict unique variance in life satisfaction beyond personality traits? Personality and Individual Differences, 50(8), 1261-1266. https://doi.org/10.1016/j.paid.2011.02.021

Zimbardo, P. G., Sword, R. M., \& Sword, R. K. M. (2012). The time cure: Overcoming PTSD with the new psychology of time perspective therapy. Jossey-Bass.

Zimbardo, P. G., \& Boyd, J. N. (1999). Putting time into perspective: A valid, reliable individual-differences metric. Journal of Personality and Social Psychology, 77(6), 1271-1288. https://doi.org/10.1037/0022-3514.77.6.1271

Ziser, K., Finklenburg, C., Behrens, S. C., Giel, K. E., Becker, S., Skoda, E.-M., Teufel, M., Mack, I., Zipfel, S., \& , Junne, F. (2019). Perceived stress mediates the relationship of body image and depressive symptoms in individuals with obesity. Frontiers in Psychiatry, $10, \quad 852$. https://doi.org/10.1026//0012-1924.47.3.142

ZPID_Leibniz Institute for Psychology Information. (2009). PSQ: Perceived Stress Questionnaire. http://dx.doi.org/ https://doi.org/10.23668/psycharchives.2889.

Publisher's Note Springer Nature remains neutral with regard to jurisdictional claims in published maps and institutional affiliations. 